\title{
CASOS CONFIRMADOS DE DENGUE NO BRASIL ENTRE OS ANOS DE 2008 A 2012
}

\section{ARTIGO ORIGINAL}

FACCO, Lucas ${ }^{1}$, MADEIRA, Laura Wanessa², FECURY, Amanda Alves ${ }^{3}$, ARAÚJO, Maria Helena Mendonça de ${ }^{4}$, OLIVEIRA, Euzébio de ${ }^{5}$, DENDASCK, Carla Viana ${ }^{6}$, SOUZA, Keulle Oliveira da ${ }^{7}$, DIAS, Claudio Alberto Gellis de Mattos ${ }^{8}$

\section{FACCO, Lucas. Et al. Casos confirmados de dengue no Brasil entre os anos de} 2008 a 2012. Revista Científica Multidisciplinar Núcleo do Conhecimento. Ano 05, Ed. 12, Vol. 10, pp. 17-27. Dezembro de 2020. ISSN: 2448-0959, Link de acesso: https://www.nucleodoconhecimento.com.br/saude/dengue-no-brasil, $\quad$ DOI: 10.32749/nucleodoconhecimento.com.br/saude/dengue-no-brasil

\section{RESUMO}

A Dengue é ocasionada por um vírus de RNA, que possui 4 variações identificadas presentes no meio humano. Suas principais manifestações sintomatológicas incluem febre, dor muscular (mialgia), dor retro ocular, dor articular (artralgia), dor de cabeça (cefaleia), náuseas, vômitos e outros, como a erupção cutânea. Este artigo objetiva mostrar o número de casos confirmados de dengue no Brasil entre os anos de 2008 a 2012. No Brasil, a dengue é caracterizada como um grande problema de saúde pública, sendo uma das doenças de caráter infeccioso deveras presente. Alguns

\footnotetext{
${ }^{1}$ Discente do Curso de Medicina da Universidade Federal do Amapá (UNIFAP).

2 Técnica em Mineração, egressa do Instituto Federal do Amapá (IFAP).

${ }^{3}$ Biomédica, Doutora em Doenças Tropicais, Professora e pesquisadora do Curso de Medicina da Universidade Federal do Amapá (UNIFAP).

${ }^{4}$ Médica, Professora e pesquisadora do Curso de Medicina da Universidade Federal do Amapá (UNIFAP).

${ }^{5}$ Biólogo, Doutor em Doenças Topicais, Professor e pesquisador do Curso de Educação Física da Universidade Federal do Pará (UFPA).

${ }^{6}$ Teóloga, Doutora em Psicanálise, pesquisadora do Centro de Pesquisa e Estudos Avançados- CEPA.

${ }^{7}$ Socióloga, Mestranda em Estudos Antrópicos na Amazônia, Integrante do Grupo de Pesquisa “Laboratório de Educação, Meio Ambiente e Saúde" (LEMAS/UFPA).

${ }^{8}$ Biólogo, Doutor em Teoria e Pesquisa do Comportamento, Professor e pesquisador do Programa de PósGraduação em Educação Profissional e Tecnológica (PROFEPT), Instituto Federal do Amapá (IFAP).
}

RC: 68974

Disponível em: https://www.nucleodoconhecimento.com.br/saude/dengue-no-brasil 
fatores, como o clima (predominantemente tropical), infraestrutura deficitária do meio urbano, além da expansão demográfica, a qual ocorre de forma desordenada, podem provocar e possivelmente justificar esse cenário nacional. Representa um grande problema de saúde pública, uma vez que o controle da doença depende do combate ao seu vetor, o qual dissemina-se com muita facilidade no país, em decorrência dos fatores climáticos e antrópicos. Para que a doença seja enfrentada de forma eficiente no país, o método mais eficaz é o combate ao vetor. O lixo e materiais devem ser separados de forma eficiente e armazenados em locais adequados para posterior reciclagem, de forma que não acumulem água e se transformem em criadouros do mosquito.

Palavras-chave: Dengue, Aedes aegypti, Epidemiologia.

\section{INTRODUÇÃO}

A Dengue é uma patologia febril ocasionada por um arbovírus, o qual faz parte da família Flaviridae (MASERA et al., 2011). A infecção do ser humano por esse vírus (RNA vírus) ocorre por meio da picada da fêmea do mosquito hematófago denominado Aedes aegypti. Esse vírus possui 4 variações identificadas, sendo elas: DENV-1, DENV-2, DENV-3 e DENV-4, sendo que o potencial de infecção do vírus em uma pessoa é de apenas uma vez para cada um desses tipos, pois o organismo desenvolve imunidade específica para cada sorotipo (XAVIER et al., 2014). Além dessas 4 variações, em 2013 foi isolado o quinto sorotipo da dengue (DENV-5), porém, ele possui um ciclo silvestre, diferentemente dos demais (MUSTAFA et al., 2014). A doença possui formas clínicas diferentes, sendo elas a Dengue Clássica, Dengue com Complicações, Febre Hemorrágica da Dengue, e, caso evolua para sua forma mais grave, pode ocorrer a Síndrome do Choque da Dengue (DIAS et al., 2010).

As principais manifestações atreladas à dengue são a febre (normalmente alta e com início que se dá de forma súbita), dor muscular (mialgia) intensa, dor retro ocular, dor articular (artralgia), dor de cabeça (cefaleia), náuseas, vômitos e outros

RC: 68974

Disponível em: https://www.nucleodoconhecimento.com.br/saude/dengue-no-brasil 
sintomas, como a erupção cutânea, sendo essa última mais comum nas infecções que ocorrem primariamente, e hemorragias de forma mais rara e podendo trazer risco de óbito ao paciente (DIAS et al., 2010).

No Brasil, ainda que existam campanhas para o controle do vetor da doença, elas não ocorrem com a eficácia necessária, uma vez que o crescimento do número de casos de dengue e mortes pela doença cresceram de forma veemente entre o período de 2000 a 2015 (ARAÚJO et al., 2017).

Os pacientes com suspeita de dengue podem ser estratificados em quatro diferentes grupos mediante fluxograma do Ministério da Saúde (grupos A, B, C e D), pautados na presença ou não de algum sinal de gravidade. Os pacientes de forma geral necessitam iniciar hidratação após detectada a suspeita de dengue, sendo que os grupos A e B recebem a hidratação via oral, enquanto os grupos $C$ e $D$ recebem hidratação via endovenosa (BRASIL, 2016).

Para que a prevenção e controle da dengue ocorram de forma eficiente, é necessário o combate assíduo do vetor, sendo que os ambientes de convivência devem ser constantemente limpos, a fim de evitar a presença de objetos que possam ser criadouros para o mosquito, na medida que acumulem água. Inseticidas também são úteis para o controle e prevenção da doença, uma vez que são capazes de eliminar o vetor, tanto em sua forma adulta quanto imatura. (FURTADO et al., 2019).

No Brasil, no ano de 2012, foram notificados 576.758 casos de dengue (mediante a variável sexo), sendo que $44 \%$ desse valor (255.069 casos) corresponderam ao sexo masculino, enquanto os $56 \%$ restantes (321.386 casos) relacionam-se ao sexo feminino. No mesmo período, o estado do Rio de Janeiro apresentou o maior número de notificações (177.798 casos), representando aproximadamente $30 \%$ de todos os casos nacionais notificados mediante o período analisado (SILVA et al., 2014).

RC: 68974

Disponível em: https://www.nucleodoconhecimento.com.br/saude/dengue-no-brasil 


\section{OBJETIVOS}

Este artigo objetiva mostrar o número de casos confirmados de dengue no Brasil entre os anos de 2008 a 2012.

\section{MÉTODO}

Resultados obtidos no site DATASUS (http://datasus.saude.gov.br). Primeiramente clicou-se na aba "acesso à informação", em seguida, selecionou-se a opção" "informações de saúde (TABNET)", logo depois clicou-se em "epidemiológicas e morbidade". Na página seguinte, selecionou-se "Doenças e Agravos de Notificação De 2007 em diante (SINAM)". Na próxima página, selecionou-se a opção "Dengue". $\mathrm{Na}$ aba "abrangência geográfica" selecionou-se a opção "Brasil por Região, UF e Município". Para a obtenção dos dados, selecionou-se no campo linha as seguintes opções: "Ano $1^{\circ}$ sintomas", "faixa etária", "Região de notificação", "sexo", "evolução de notificação", "notificações por gestantes", "zona de residência", "notificação por escolaridade" e "notificação por class. final". Para todas as opções acima foram selecionados no campo coluna a opção "não ativa"; no campo "conteúdo", a opção "casos confirmados"; e em períodos disponíveis dados de 2008 a 2012.Os gráficos dos dados foram feitos dentro do aplicativo Excel, componente do pacote Office da Microsoft Corporation. A pesquisa bibliográfica foi realizada em artigos científicos, utilizando-se para busca computadores do laboratório de informática do Instituto Federal de Educação, Ciência e Tecnologia do Amapá, Campus Macapá, situado na: Rodovia BR 210 KM 3, s/n - Bairro Brasil Novo. CEP: 68.909-398, Macapá, Amapá, Brasil.

\section{RESULTADOS}

A figura 1 mostra a porcentagem de casos confirmados de dengue no Brasil entre os anos de 2008 a 2012, por ano. A maior porcentagem ocorreu no ano de 2010 (30,51\%), seguido por 2011 (21,34\%), 2012 (18,01\%), 2008 (17,39\%) e, por fim, $2009(12,75 \%)$.

RC: 68974

Disponível em: https://www.nucleodoconhecimento.com.br/saude/dengue-no-brasil 
Figura 1 Mostra a porcentagem de casos confirmados de dengue no Brasil entre os anos de 2008 a 2012, por ano.

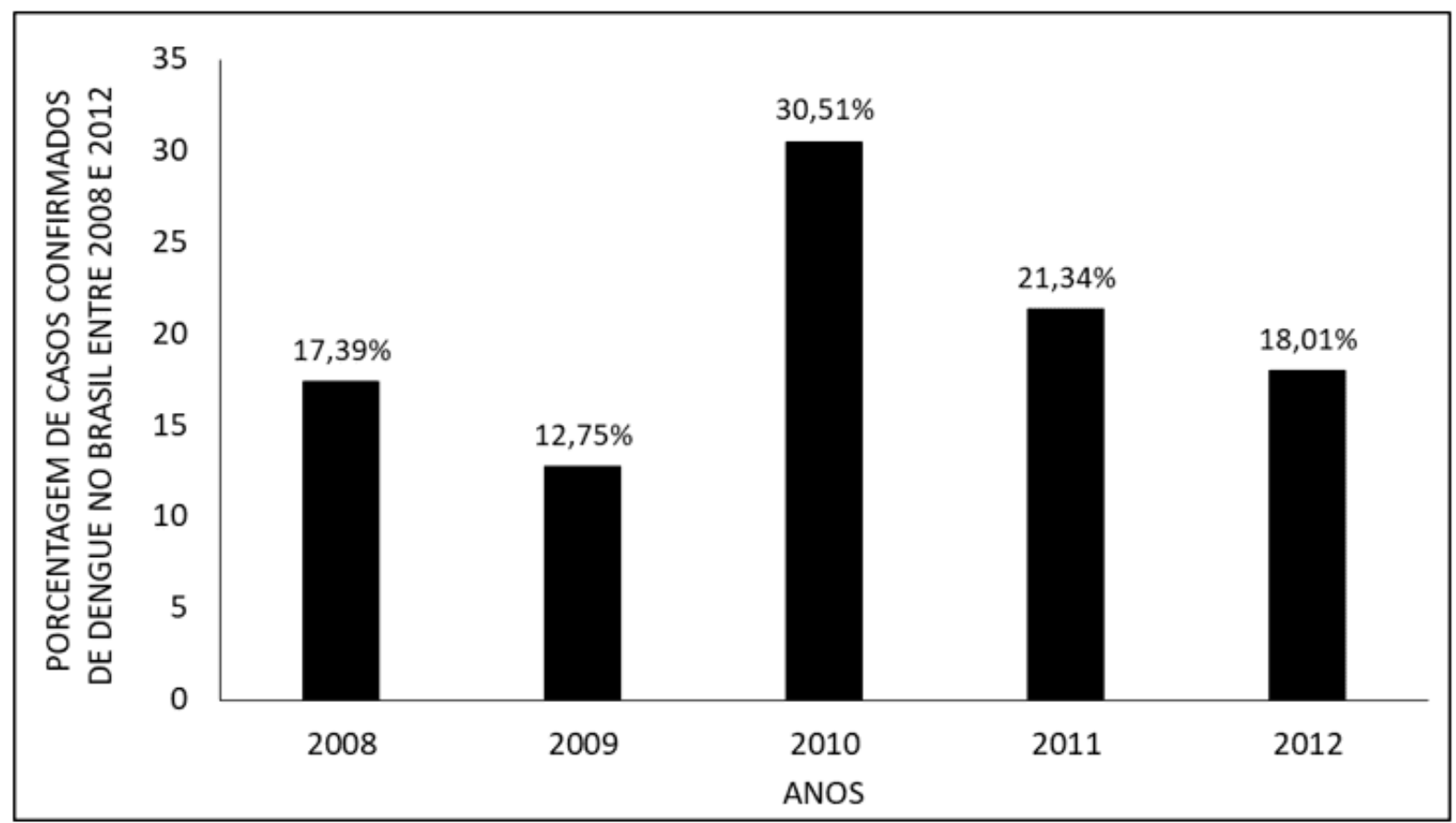

A figura 2 mostra a porcentagem de casos confirmados de dengue no Brasil entre os anos de 2008 a 2012, por regiões do país. No período em estudo, a região Sudeste apresentou a maior porcentagem de casos $(44,77 \%)$, seguido pelo Nordeste (26,99\%), Centro-Oeste (14,69\%), Norte $(11,09 \%)$ e Sul $(2,47 \%)$.

RC: 68974

Disponível em: https://www.nucleodoconhecimento.com.br/saude/dengue-no-brasil 
Figura 2 Mostra a porcentagem de casos confirmados de dengue no Brasil entre os anos de 2008 a 2012, por regiões do país.

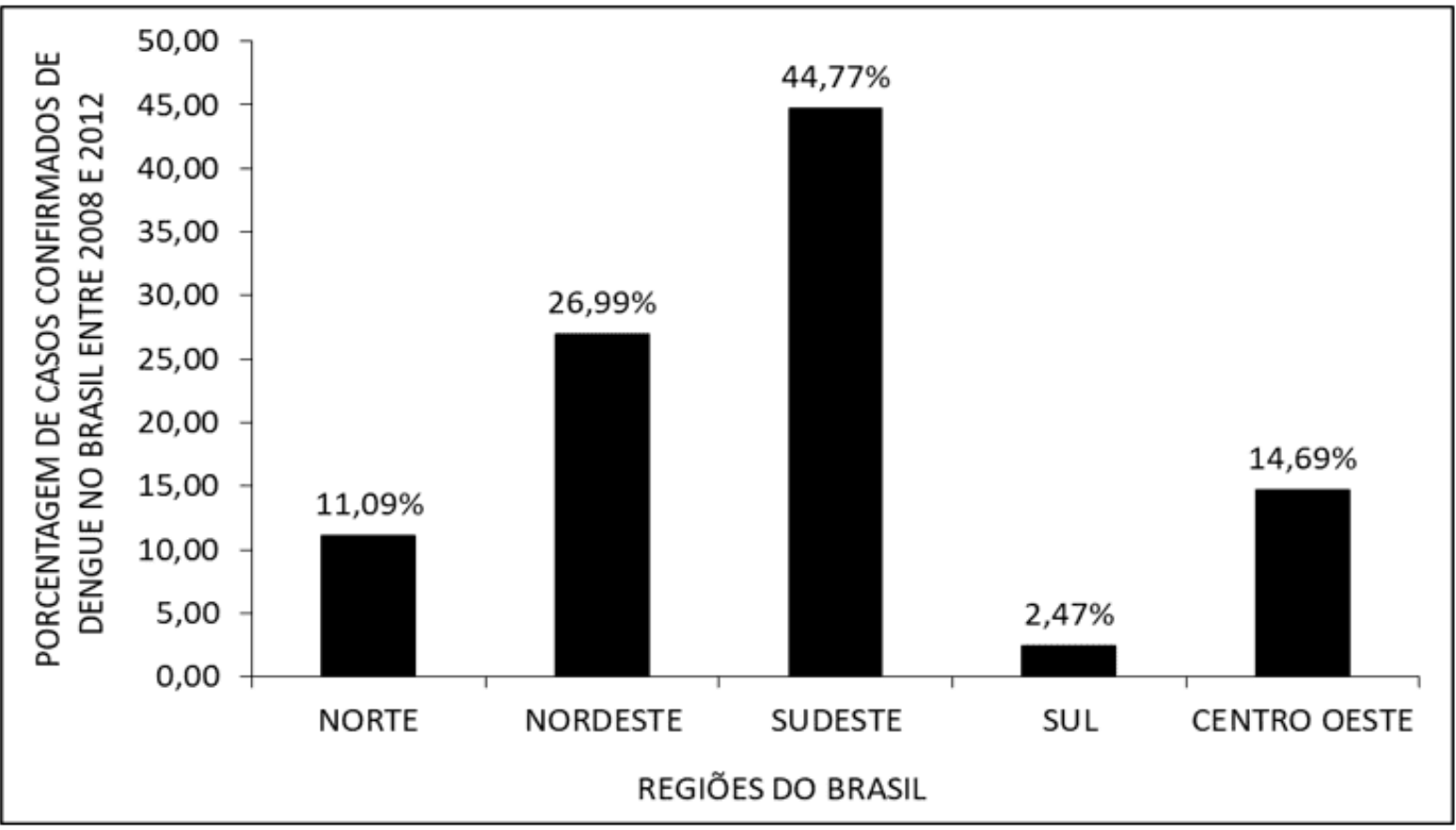

A figura 3 mostra a porcentagem de casos confirmados de dengue no Brasil entre os anos de 2008 a 2012, por zona de residência. A zona urbana apresentou ampla porcentagem dos casos $(87,18 \%)$, sendo que a porcentagem da zona rural foi significativamente menor $(5,07 \%)$. Além disso, $0,38 \%$ dos casos ocorreram na região periurbana e $7,37 \%$ não foram determinados.

RC: 68974

Disponível em: https://www.nucleodoconhecimento.com.br/saude/dengue-no-brasil 
Figura 3 Mostra a porcentagem de casos confirmados de dengue no Brasil entre os anos de 2008 a 2012, por zona de residência.

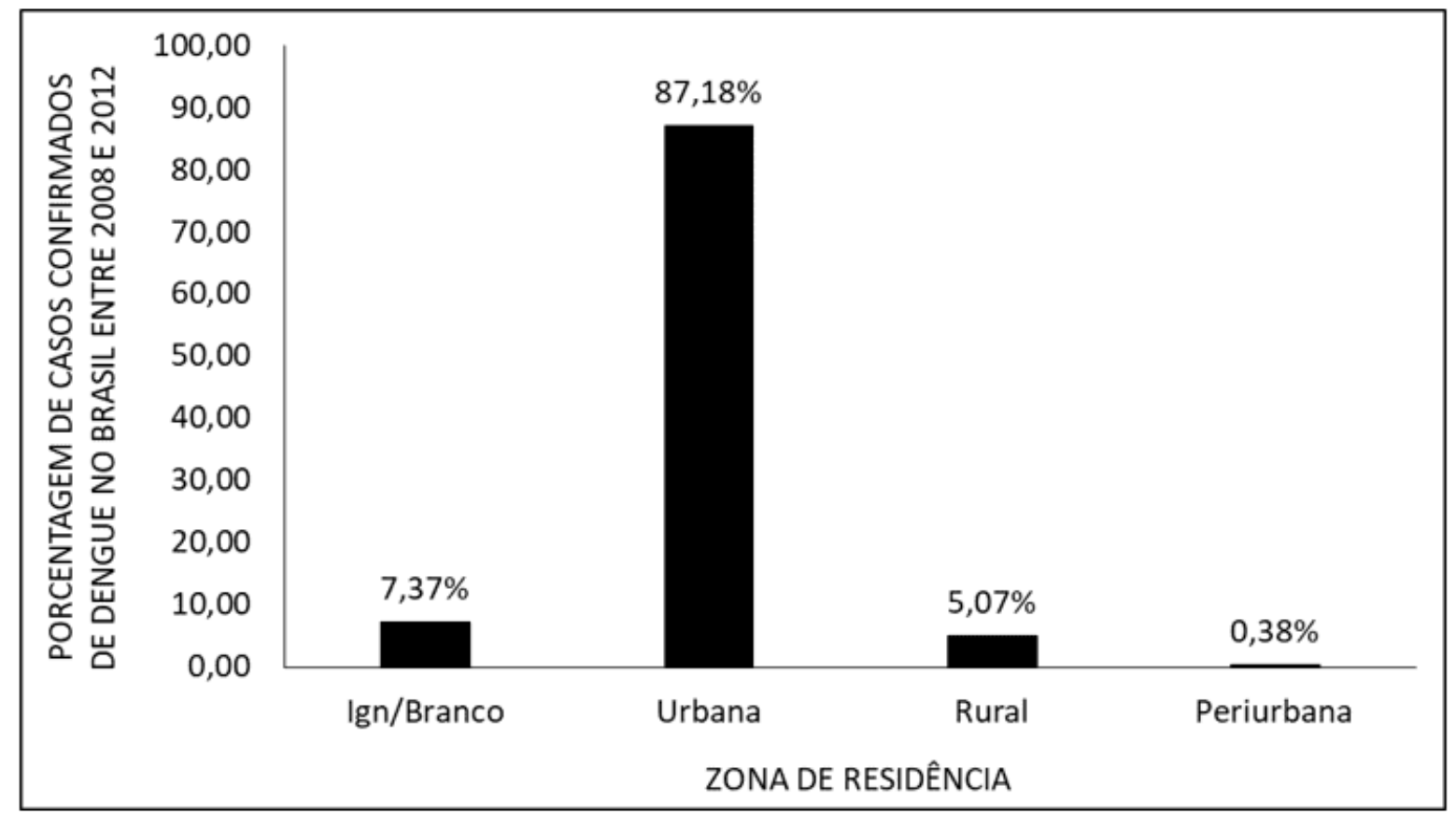

A figura 4 mostra a porcentagem de casos confirmados de dengue no Brasil entre os anos de 2008 a 2012, por faixa etária. Nota-se que, durante o período estudado, a faixa etária com a maior porcentagem de casos foi a de 20 a 39 anos $(38,28 \%)$, seguida por 1 a 19 (30,84\%), 40 a $59(21,93 \%), 60$ a $69(4,55 \%), 70$ a 79 anos $(2,02 \%),<1$ ano $(1,61 \%)$ e 80 ou mais $(0,60 \%)$. Além disso, $0,15 \%$ dos casos não tiveram sua faixa etária determinada.

RC: 68974

Disponível em: https://www.nucleodoconhecimento.com.br/saude/dengue-no-brasil 
Figura 4 Mostra a porcentagem de casos confirmados de dengue no Brasil entre os anos de 2008 a 2012, por faixa etária.

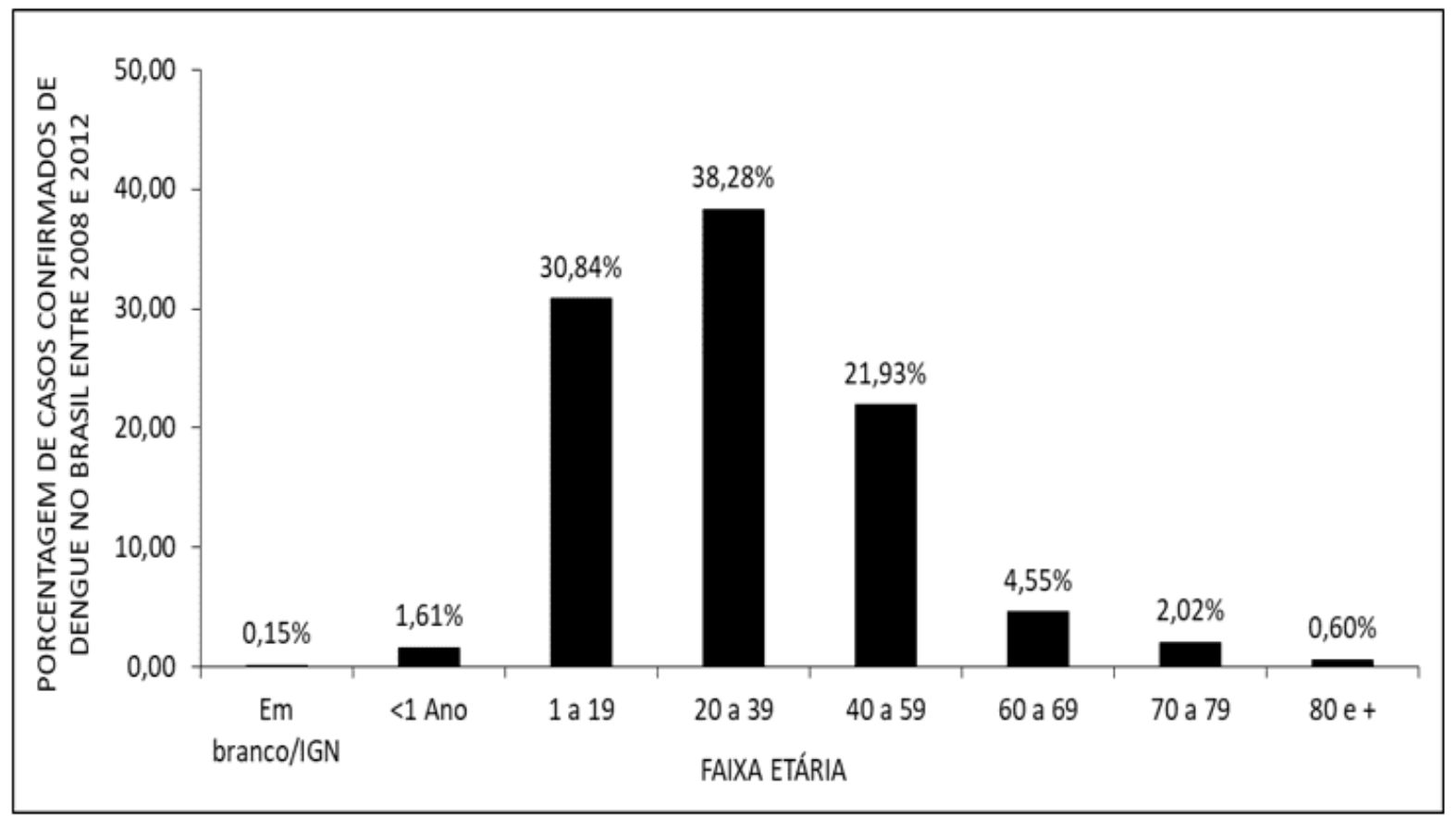

A figura 5 mostra a porcentagem de casos confirmados de dengue no Brasil entre os anos de 2008 a 2012, pela escolaridade. O maior valor dos casos ocorreu na categoria de escolaridade Ensino médio completo (17,65\%), seguida por $5^{\circ}$ a $8^{\circ}$ série incompleta de Ensino fundamental (EF) (17,59\%), $1^{\circ}$ a $4^{\circ}$ série incompleta do EF (12,17\%), Ensino médio incompleto (10,44\%), Ensino fundamental completo $(8,49 \%), 4^{\circ}$ série incompleta do EF (7,23\%), Educação superior completa $(4,50 \%)$, Educação superior incompleta $(2,95 \%)$ e analfabeto $(1,81 \%)$. $17,18 \%$ do total encaixou-se na categoria "Não se aplica".

RC: 68974

Disponível em: https://www.nucleodoconhecimento.com.br/saude/dengue-no-brasil 
Figura 5 Mostra a porcentagem de casos confirmados de dengue no Brasil entre os anos de 2008 a 2012, pela escolaridade.

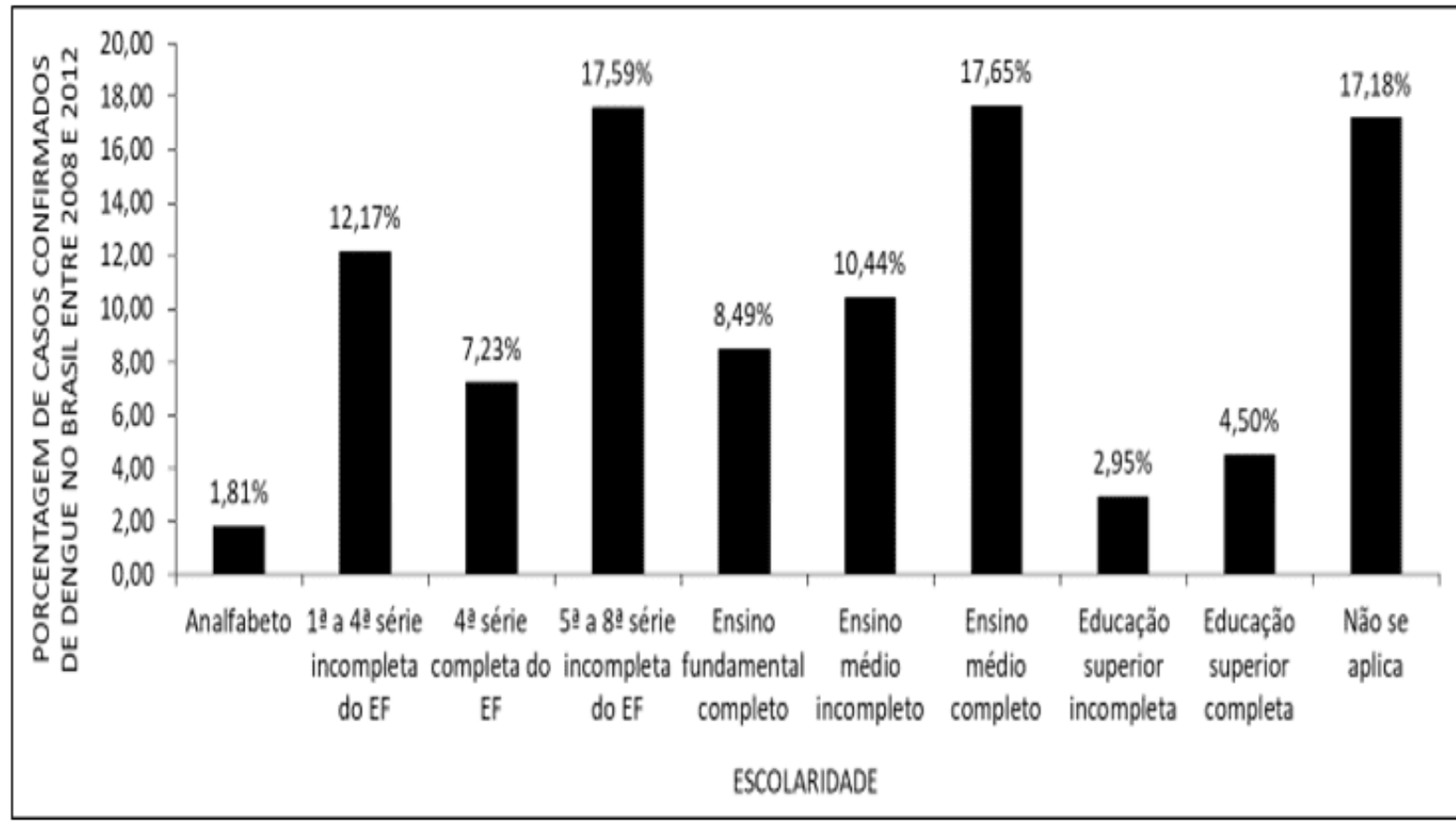

A figura 6 mostra a porcentagem de casos confirmados de dengue no Brasil entre os anos de 2008 a 2012, por gênero. Nota-se que a porcentagem de casos confirmados durante o período em análise foi superior entre o gênero feminino $(55,08 \%)$, enquanto o masculino representou, $44,92 \%$ dos casos.

RC: 68974

Disponível em: https://www.nucleodoconhecimento.com.br/saude/dengue-no-brasil 
Figura 6 Mostra a porcentagem de casos confirmados de dengue no Brasil entre os anos de 2008 a 2012, por gênero.

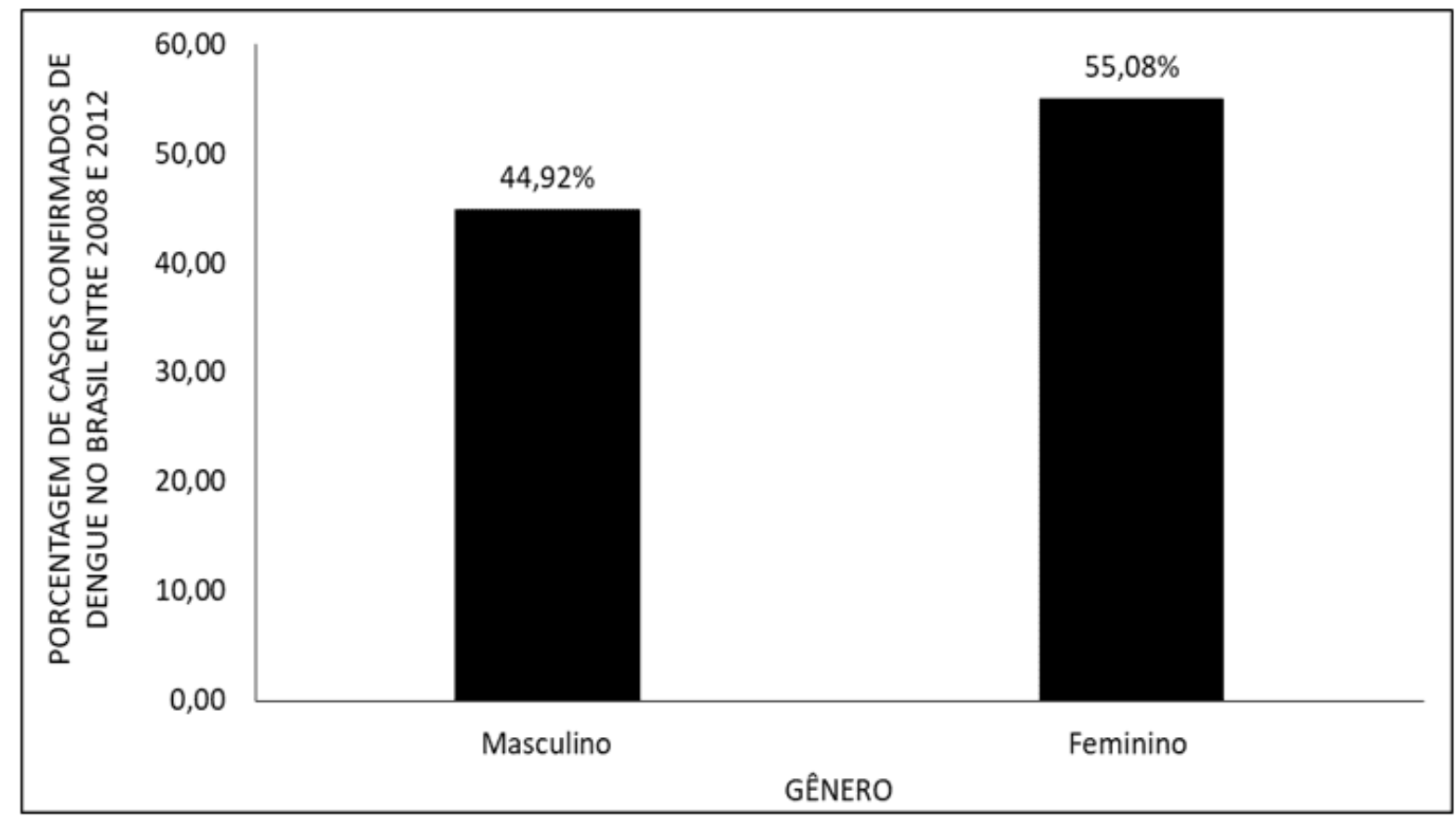

A figura 7 mostra a porcentagem de casos confirmados de dengue no Brasil entre os anos de 2008 a 2012, pela idade gestacional. $30,26 \%$ dos casos corresponderam ao $2^{\circ}$ trimestre de idade gestacional, seguido pelo $1^{\circ}$ trimestre $(26,01 \%)$ e $3^{\circ}$ trimestre $(23,53 \%) .20,21 \%$ dos casos tiveram a idade gestacional ignorada.

RC: 68974

Disponível em: https://www.nucleodoconhecimento.com.br/saude/dengue-no-brasil 
Figura 7 Mostra a porcentagem de casos confirmados de dengue no Brasil entre os anos de 2008 a 2012, pela idade gestacional.

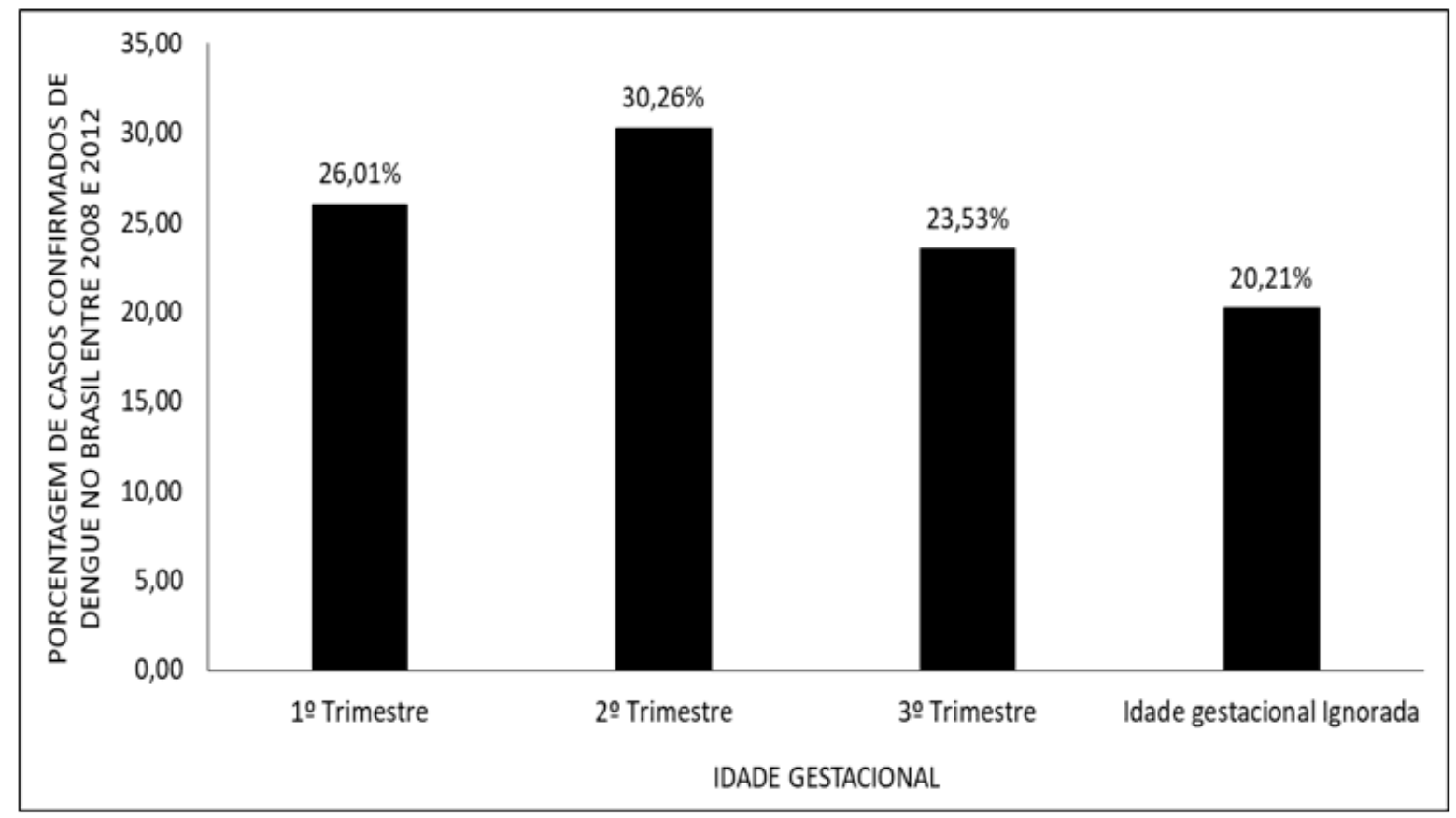

A figura 8 mostra a porcentagem de casos confirmados de dengue no Brasil entre os anos de 2008 a 2012, pela classificação final dos casos. Nota-se um valor amplamente maior para Dengue Clássico (51,33\%), seguido por Dengue com complicações (22,39\%), Inconclusivo (13,99\%), Síndrome do choque da Dengue $(10,80 \%)$ e Febre Hemorrágica da Dengue $(0,29 \%)$. 1,00\% dos casos não foram especificados (Ign/Branco).

RC: 68974

Disponível em: https://www.nucleodoconhecimento.com.br/saude/dengue-no-brasil 
Figura 8 Mostra a porcentagem de casos confirmados de dengue no Brasil entre os anos de 2008 a 2012, pela classificação final dos casos.

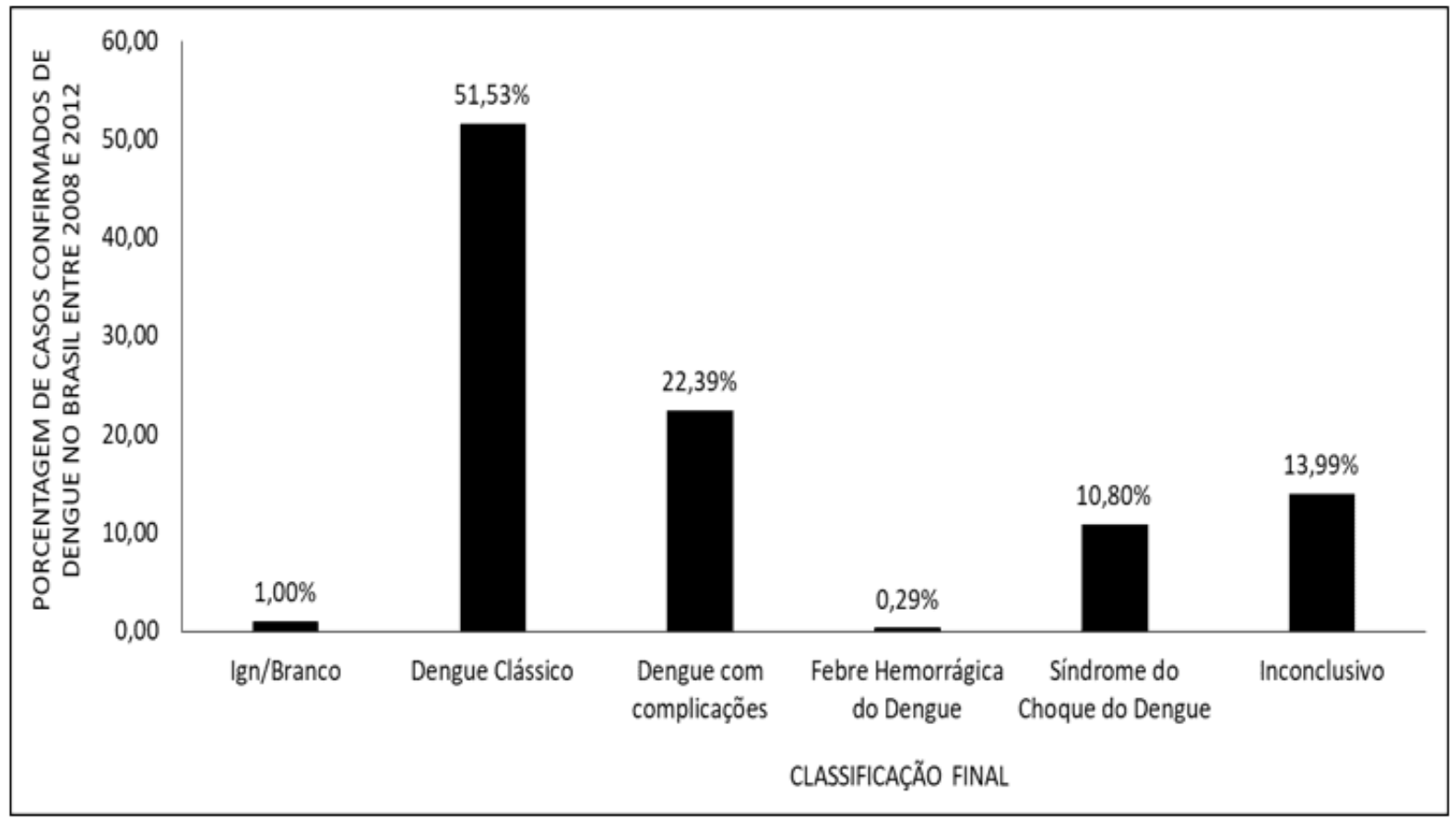

A figura 9 mostra a porcentagem de casos confirmados de dengue no Brasil entre os anos de 2008 a 2012, pela evolução dos casos. Ampla maioria dos casos evoluíram com Cura $(71,68 \%)$, seguida por $0,07 \%$ de Óbitos pelo agravo notificado, $0,02 \%$ de Óbitos por outra causa e $0,01 \%$ de Óbitos em investigação. $28,23 \%$ dos casos não foram especificados (Ign/Branco).

RC: 68974

Disponível em: https://www.nucleodoconhecimento.com.br/saude/dengue-no-brasil 
Figura 9 Mostra a porcentagem de casos confirmados de dengue no Brasil entre os anos de 2008 a 2012, pela evolução dos casos.

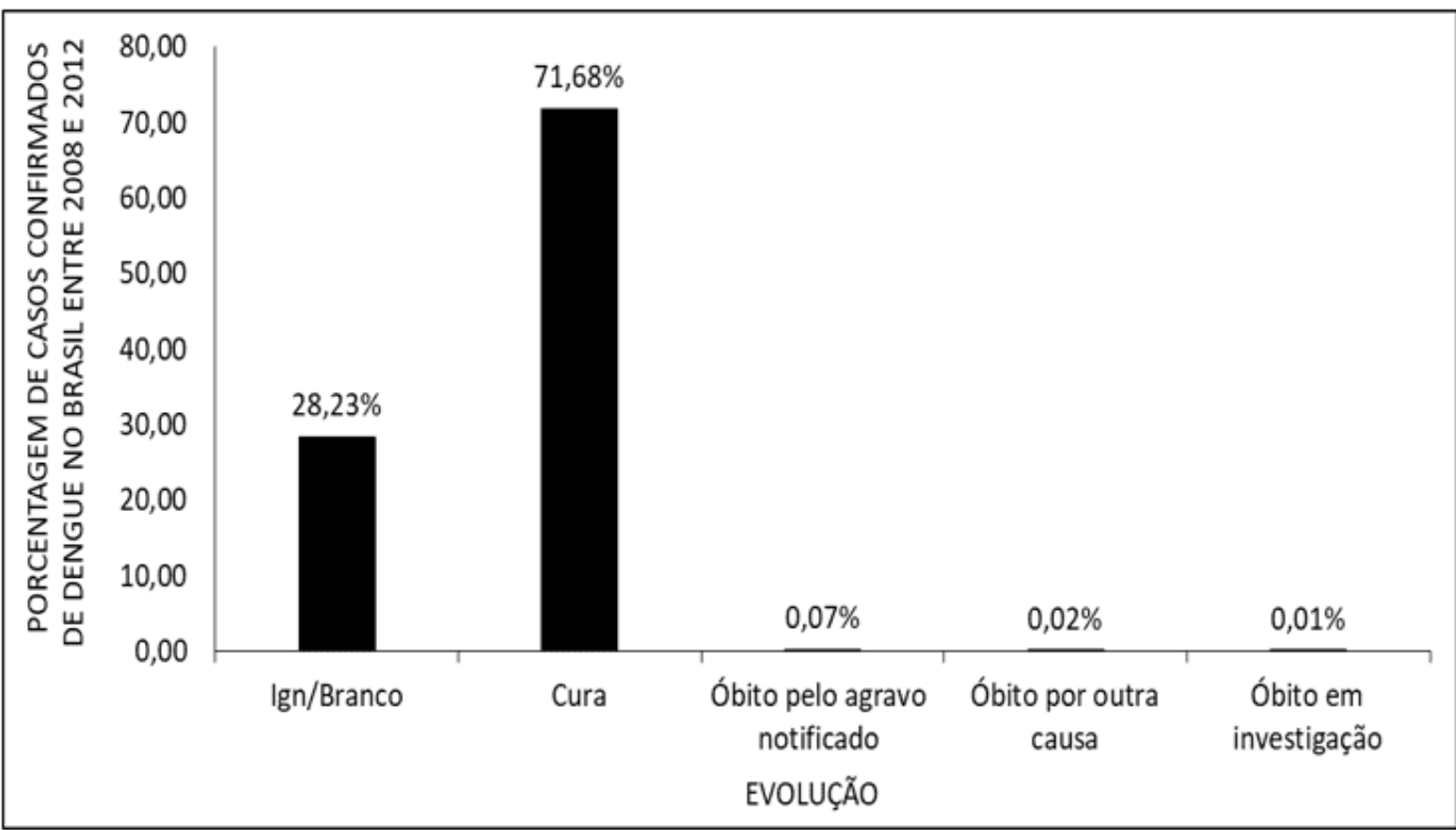

\section{DISCUSSÃO}

No Brasil, a dengue é caracterizada como um grande problema de saúde pública, sendo uma das doenças de caráter infeccioso deveras presente. Alguns fatores, como o clima (predominantemente tropical), infraestrutura deficitária do meio urbano, além da expansão demográfica, a qual ocorre de forma desordenada (COSTA e CALADO, 2016), podem provocar e possivelmente justificar esse cenário nacional, caracterizando o agravo no número de casos entre o período de 2009 para 2010, sendo que a maior porcentagem das notificações, tendo em vista o período estudado, ocorre em 2010.

Dentre as regiões geográficas brasileiras, a que apresenta o maior número de casos de dengue é a Sudeste, sendo que o estado com o maior valor percentual de casos é o Rio de Janeiro, sendo que esse, no ano de 2012, representou cerca $30 \%$ dos casos nacionais. A região Sudeste é a região que apresenta o maior grau de

RC: 68974

Disponível em: https://www.nucleodoconhecimento.com.br/saude/dengue-no-brasil 
urbanização, sendo que o Rio de janeiro apresenta visível desordem em seu crescimento urbano, uma vez que nota-se a ampliação das favelas e, concomitantemente, da segregação socioespacial, fatores que deflagram a desigualdade e dificuldade de vivência local, uma vez que as condições de saneamento muito precárias favorecem a proliferação do mosquito Aedes Aegypti, vetor da dengue (SILVA et al., 2014).

A ampla maioria dos casos de dengue ocorre na região urbana, sendo que, no período em estudo, representou quase $90 \%$ dos casos totais. A região urbana apresenta constante crescimento e desenvolvimento, porém, nem sempre o mesmo ocorre de forma adequada, favorecendo o aumento de criadouros para o vetor. Um dos fatores que podem explicar esse aumento seria a coleta ineficiente de lixo, uma vez que nem todas as localidades são contempladas da mesma maneira e, dessa forma, principalmente os materiais descartáveis, podem favorecer o acúmulo de água e geram um ambiente propício de proliferação do mosquito. Além disso, as residências localizadas nos centros urbanos são muito próximas, dessa forma, caso haja focos do vetor em uma casa, as habitações vizinhas também estarão sujeitas à dengue, proporcionando ainda uma maior facilidade para a dispersão do mosquito por vários ambientes (HORTA et al., 2013).

A faixa etária cujo percentual de notificações foi mais abrangente é a de 20 a 39 anos, característica que é corroborada em outros estudos, denotando o aumento da incidência de casos mediante o aumento de idade, sendo que esse aumento estabiliza na faixa etária entre 30 e 39 anos, diminuindo de forma significativa a partir dela (RIBEIRO et al., 2006). Além disso, nota-se que a maior incidência ocorre em pacientes cuja escolaridade apresentada remete ao ensino médio completo, fator apoiado por outros estudos epidemiológicos que mostram que pacientes apresentavam de 6 a 9 anos de estudo, bem como pacientes com 10 ou mais anos de estudo, demonstravam maior quantidade de anticorpos para a dengue, ou seja, foram acometidos pela patologia (TAVARES, 2014).

$\mathrm{RC}: 68974$

Disponível em: https://www.nucleodoconhecimento.com.br/saude/dengue-no-brasil 
O maior número de casos notificados abrange o sexo feminino, representando aproximadamente $55 \%$ do total dentro do período em estudo. Um dos possíveis fatores que podem explicar tais dados é o maior período de tempo que estão em suas residências, uma vez que o ambiente domiciliar é o local onde mais ocorre a transmissão da dengue (SILVA et al., 2014)

No período em questão (2008 a 2012), o maior número de notificações ocorreu em gestantes no segundo trimestre de gravidez. As gestantes também podem contrair dengue, devendo ser monitoradas de forma constante nesses casos, uma vez que a dengue durante a gestação pode ocasionar problemáticas na evolução gestacional, como a ocorrência de hemorragias, eclampsia e pré-eclâmpsia. Dentre esses, a hemorragia atrelada a trombocitopenia, além de infecções agudas e danos à placenta no primeiro trimestre de gestação, representam as principais causas de óbito em gestantes com dengue. Dessa forma, nota-se que as gestantes se caracterizam como grupo que apresenta vulnerabilidade acentuada para o quadro de dengue, tanto em relação à evolução da doença com complicações, quanto à possibilidade de óbito materno em decorrência dessa patologia. Deve-se ressaltar, no entanto, que ainda que possa haver tais complicações durante a gestação, a dengue não costuma estar atrelada à malformações congênitas (NASCIMENTO et al., 2017).

A dengue apresenta diferentes formas clínicas, sendo tais a Dengue Clássica, dengue com Complicações, Febre Hemorrágica da Dengue, e, caso o paciente evolua de forma negativa, pode apresentar-se em sua forma mais grave, ocorrendo então a Síndrome do Choque da Dengue. Dentre elas, a mais prevalente é a clássica, sendo que o paciente costumeiramente apresenta febre alta de forma súbita, dores de cabeça (cefaleias), dor muscular (mialgia), dor articular (artralgia), fraqueza e outros sintomas, como náuseas, vômitos, erupção cutânea (que ocorrem principalmente em infecções primárias e dor retro orbitária. Além disso, mesmo na forma clássica da doença, os pacientes podem apresentar hemorragias, as quais podem ocorrer de forma espontânea, como sangramentos nasais (epistaxe),

RC: 68974

Disponível em: https://www.nucleodoconhecimento.com.br/saude/dengue-no-brasil 
gengivais, e o surgimento de petéquias, ou provocadas (mediante a realização da prova do laço, caso seja positiva) (DIAS et al., 2010).

A forma mais grave da dengue é chamada Febre Hemorrágica da Dengue, ou simplesmente dengue hemorrágica, e, caso não seja manejada de forma eficiente e ágil, pode evoluir para Síndrome do Choque da Dengue, caracterizada pelo choque do sistema circulatório do paciente, podendo levá-lo rapidamente a óbito. Determinados sinais são considerados como "alarme" para a equipe responsável pelo atendimento do paciente (hipotensão postural e arterial, hemorragias, vômitos constantes, diurese diminuída, hematócrito aumentado e entre outros, como diurese diminuída), mediante tais sinais, seguindo as orientações do Ministério da Saúde, os pacientes podem ser divididos em 4 grupos ( $A, B, C$ e $D)$, dos casos menor para maior complicação, de modo a orientar a conduta terapêutica, sendo que os grupos A e B não apresentam sinais de gravidade, enquanto os grupos C e D apresentam tais sinais (DIAS et al., 2010 e BRASIL, 2016).

\section{CONCLUSÃO}

A Dengue é uma patologia transmitida pelo mosquito Aedes Aegypti, possuindo quatro sorotipos que fazem parte do ciclo humano (DENV-1, DENV-2, DENV-3, DENV-4). No Brasil, representa um grande problema de saúde pública, uma vez que o controle da doença depende do combate ao seu vetor, o qual dissemina-se com muita facilidade no país, em decorrência dos fatores climáticos e antrópicos, como a urbanização desordenada e o consequente problema sanitário de acúmulo de lixo e objetos descartáveis nos ambientes públicos e até mesmo residenciais, facilitando a proliferação de criadouros do mosquito e sua consequente multiplicação.

Nota-se que a região mais afetada pela dengue é a Sudeste, tendo em vista a abrangência de sua área urbana, sendo que o estado com o maior índice de notificações é o Rio de Janeiro, tendo em vista o amplo processo de segregação socioespacial que lá ocorre, com grande abrangência de favelas e falta de

$\mathrm{RC}: 68974$

Disponível em: https://www.nucleodoconhecimento.com.br/saude/dengue-no-brasil 
infraestrutura e saneamento básico, resultando em uma quantidade elevada de criadouros do vetor.

Possuindo quatro principais apresentações clínicas (Dengue Clássica, Dengue com Complicações, Febre Hemorrágica da Dengue e Síndrome do Choque da Dengue), a mais prevalente de todas é a Dengue Clássica, na qual os pacientes não costumam apresentar sinais de gravidade. A depender da apresentação sintomatológica do paciente, de acordo com o Ministério da Saúde, ele deverá ser classificado dentre quatro grupos ( $A, B, C$ e $D)$, sendo que seu esquema terapêutico derivará de tal classificação. O paciente deve receber hidratação e ser manejado de forma adequada, para que não evolua negativamente e evitar, dessa maneira, a forma mais complicada da doença.

Gestantes apresentam-se como grupo vulnerável para a dengue, sendo que a doença pode, a depender do trimestre de gravidez, gerar diferentes consequências negativas para a saúde da mãe, de modo a colocar em risco sua vida. A dengue não é classificada como causadora de malformações congênitas.

Para que a doença seja enfrentada de forma eficiente no país, o método mais eficaz é o combate ao vetor. O lixo e materiais devem ser separados de forma eficiente e armazenados em locais adequados para posterior reciclagem, de forma que não acumulem água e se transformem em criadouros do mosquito.

\section{REFERENCIAS}

ARAÚJO, V. E. M.; BEZERRA, J. M. T.; AMÂNCIO, F. F.; PASSOS, V. M. A.; CARNEIRO, M. Aumento da carga de dengue no Brasil e unidades federadas, 2000 e 2015: análise do Global Burden of Disease Study 2015. Rev Bras Epidemiol, suppl 1, p. 205-216, 2017.

BRASIL. Dengue: diagnóstico e manejo clínico: adulto e criança. Brasilia DF: Ministério da Saúde. 58 p. 2016. Disponível em: 
$<$ https://portalarquivos2.saude.gov.br/images/pdf/2016/janeiro/14/dengue-manejoadulto-crianca-5d.pdf>. Acesso em: 13 Dezembro 2020.

COSTA, I. M. P.; CALADO, D. C. Incidência dos casos de dengue (2007-2013) e distribuição sazonal de culicídeos (2012-2013) em Barreiras, Bahia. Epidemiol Serv Saude, v. 25. N. 4, p. 735-744, 2016.

DIAS, L. B. A.; ALMEIDA, S. C. L.; HAES, T. M.; MOTA, L. M.; RORIZ-FILHO, J. S. Dengue: transmissão, aspectos clínicos, diagnóstico e tratamento. Medicina (Ribeirão Preto), v. 43, n. 2, p. 142-152, 2010.

FURTADO, A. N. R.; LIMA, A. S. F.; OLIVEIRA, A. S.; TEIXEIRA, A. B.; FERREIRA, D. S.; OLIVEIRA, E. C.; CAVALCANTI, G. B.; SOUSA, W. A.; LIMA, W. M. Dengue e seus avanços. RBAC, v. 52, n. 3, p. 196-201, 2019.

HORTA, M. A. P.; FERREIRA, A. P.; OLIVEIRA, R. B.; WERMELINGER, E. D.; KER, F. T. O.; FERREIRA, A. C. N.; CATITA, C. M. S. Os efeitos do crescimento urbano sobre a dengue. Revista Brasileira em Promoção da Saúde, v. 26, n. 4, p. 539549, 2013.

MASERA, D. C.; SCHENKEL, G. C.; SILVA, L. L.; SPANHOL, M. R.; FRACASSO, R.; BONOTTO, R. M.; LARA, G. M. Febre Hemorrágica da Dengue: Aspectos Clínicos, Epidemiológicos e Laboratoriais de uma Arbovirose. Revista Conhecimento Online, v. 2, p. 1-22, 2011.

MUSTAFA, M. S.; RASOTGI, V.; JAIN, S.; GUPTA, V. Discovery of fifth serotype of dengue vírus (DENV-5): A new public health dilema in dengue control. Medical Journal Armed Forces India, v. 71, n. 1, p. 67-70, 2015.

NASCIMENTO, L. B.; SIQUEIRA, C. M.; COELHO, G. E.; SIQUEIRA JÚNIOR, J. B. Dengue em gestantes: caracterização dos casos no Brasil, 2007-2015. Epidemiol Serv Saude, v. 26, n. 3, p. 433-442, 2017.

RC: 68974

Disponível em: https://www.nucleodoconhecimento.com.br/saude/dengue-no-brasil 
RIBEIRO, A. F.; MARQUES, G. R. A. M.; VOLTOLINI, J. C.; CONDINO, M. L. F. Associação entre incidência de dengue e variáveis climáticas. Rev Saúde Pública, v. 40 , n. 4 , p. 671-676, 2006.

SILVA, E. M.; JESUS, S. R. R.; FONSECA, I. S. S. Epidemiologia da Dengue no Brasil no ano de 2012. Ciências Biológicas e da Saúde, v. 2, n. 2, p. 69-78, 2014.

TAVARES, A. S. Prevalência e Incidência de Infecção pelo Vírus da Dengue em uma Comunidade Urbana: Um Estudo de Coorte. Dissertação (Mestrado em Biotecnologia em Saúde e Medicina Investigativa) - Fundação Oswaldo Cruz, Bahia, Salvador, 2014.

XAVIER, A. R.; FREITAS, M. S.; LOUREIRO, F. M.; BORGHI, D. P.; KANAAN, S. Manifestações clínicas na dengue, Diagnóstico Laboratorial. JBM, v. 102, n. 2, p. 714, 2014.

Enviado: Dezembro, 2020.

Aprovado: Dezembro, 2020.

RC: 68974

Disponível em: https://www.nucleodoconhecimento.com.br/saude/dengue-no-brasil 